\title{
HUMANISMO CLASICISTA MEDITERRÁNEO Y CONCEPCIÓN ANTROPOLÓGICA DEL MUNDO: EL CASO DE LOS JESUTTAS
}

por

FERMÍN DEL PINO

Instituto de Filología, C.S.J.C.

RESUMEN: Se propone por el autor una reconsideración del papel de los jesuitas en la historia cientifica de la España Modema, con énfasis principal en su contribución lingüística y etnográfica. Se elige el caso jesuita para poner a prueba las nuevas teortas surgidas en el último cuarto de siglo sobre la importancia cientifica del humanismo clasicista, (Lopez Piñero, John Rowe, Reinhard...) nacido alrededor de la Europa mediterránea pero proyectado luego sobre todo el mundo. La hipótesis es especialmente verdad en el caso de la Lingütstica y la Etnografía, puesto que el surgimiento de la consciencia de otras lenguas y humanidades -igualmente dignas, aunque no mediterráneas-parecio ser realmente una "invencion" moderna, no heredada de los clásicos.

Palabras clave. Jesuítas. Renactimiento. Misiones. Antropologia Cultural. Historia de la Clencia. América. España Moderma. Mediterráneo.

ABSTRACT: The aim of this article is to reconsider the role played by the jesuits in the history of science in Early Modern Spain, with special attention to their contribution to linguistics and etnograhpy. The jesuits have been chosen for testing the new theories made in the last quarter of our century on the scientific importance of the classical humanisme, bomed in the mediterranean Europe but extended all over the world afterwards. This hypothesis is particularly correct regarding those disciplines, because it seems that the arising of the European conscience on other languages and cultures - with similar dignity, though not being mediterranean origin-was a modern "invention" and not a classical heritage.

Key Words: Cultural Anthropology. History of Sciences. Renaissance. Jesutts. Missions. Early Modern Spain. Mediterranean Sea. America. 
He creído oportuno elegir este caso jesuítico, para participar en un número monográfico sobre la historia social y cultural del Mediterráneo, por varios motivos. Quizás el más decisivo sea mi familiaridad con la obra de algunos jesuitas en relación con la etnografía del Nuevo Mundo ${ }^{1}$. Pero creo que también se relaciona objetivamente la orden de San Ignacio con algunos temas relevantes para este foro historiográfico. Por ejemplo, con el de la ciencia española durante la Edad Moderna, puesto que la Compañía estuvo muy ligada a la labor cultural de la Corona: desde 1625 dirigian los Reales Estudios en su Colegio imperial, obedeciendo a una propuesta del Conde-Duque para modernizar a la nobleza ( $y$ resistido de su parte por ello mismo), y entre 1625 y 1767 estuvieron encargados de oficio de describir para la Corona la cosmografía del Nuevo Mundo. También necesitó la Compañía de la ciencia para sí misma, desde su fundación en 1540, puesto que su propia estrategia de "conquista espiritual» - a la fe por la razón- requería especialmente un conocimiento detallado del mundo.

Recuerdo a este respecto también el énfasis sociológico manifestado por parte de algunos equipos españoles de "historia de la ciencia" (Laín, López Piñero, Peset, Lafuente, etc.) en favor del estudio de los grupos, las instituciones y los largos períodos, por contraste con los «héroes» aislados y fugaces. Si hemos de elegir una corporación, que esté además bien organizada y ligada a instituciones estables - y no una suma de individualidades heroicas, o un grupo institucional de labor discontínua, como ha sido el caso más frecuente en nuestra historia cultural-, no cabe duda que la Compañía de Jesús es pertinente. Como grupo intelectual y ade presión» en la España del Antiguo Régimen (1540-1767), es posiblemente el que más haya destacado, y es indudable que su influencia cultural se ha sostenido a un nivel más internacional, y con más continuidad que otros. Ellos dominaron por mucho tiempo tanto la escena nacional como la internacional, dirigiendo o influyendo de modo importante sobre la aristocracia y la monarquía, tanto en España como en Francia, Italia y Portugal $-\mathrm{y}$ en el universo europeo creado sobre territorios de Africa, Asia, América y Oceania-. Sin dejar por ello de intervenir indirectamente en Inglaterra, y centro de Europa.

$\mathrm{Si}$ hemos de atenernos a la experiencia historiográfica derivada de algunos estudios recientes sobre la producción e institucionalización científica entre el XVI y el XVIII -como, por ejemplo, los análisis de M. Esteban Piñero respecto

1 Además de mis estudios personales sobre la obra científica del P. José de Acosta y de otros jesuitas, quiero mencionar el hecho de haber coordinado a mediados de los 80 un seminario titulado como la obra famosa del P. Acosta, "Historia natural y moral de las Indias». En él se pudo dar a conocer una serie de trabajos de los siglos XVI al XIX, en una gran parte jesuitas, que unian las ciencias naturales con las del hombre en una mezcla aún babitual dentro de la disciplina antropológica - la única todavía a caballo entre las Humanidades y las Ciencias Naturales. Si alguna vez ven la luz en conjunto - puesto que individualmente algunos ya lo ban hecho-, se podrá entender mejor mi propuesta de considerar la contribución jesuita como una de las empresas antropológicas más firmes de la tradición científica hispana.

Hispania, LVI/, num. 192 (1996) 29-50 
de la labor de política científica de Felipe II, o también los estudios de muchos colegas nuestros del C.S.I.C. sobre las expediciones ilustradas--, es probable que la ciencia en España, y desde luego en Castilla, haya estado a cargo del Estado $^{2}$. Bien es verdad que esta influencia oficial de un grupo social determinado no ha perdurado luego del mismo modo, a partir de la crisis de la institución monárquica a comienzos del siglo XIX. Sin embargo, tampoco puede decirse que los nuevos grupos de presión no hayan querido seguir influyendo en la marcha cultural nacional a través del Estado: quizás no se realice ya principalmente a través de órdenes religiosas o de grupos aristocráticos, sino de otros grupos de poder o incluso de los gremios profesionales, como abogados, médicos, ingenieros, militares, etc. Lo que ocurre en el XIX y xX con grupos ideológicos como la Institución Libre de Enseñanza, o el movimiento catalán llamado «Noucentisme», no es en realidad tan diferente de las pretensiones de los jesuítas, en cuanto que también ellos se pretendían establecer como base social alternativa de apoyo reformista al proyecto oficial nacionalista, y desde ahí aspiraban a su modo a una cierta «conquista del Estadon: la burguesía que sucede al sistema estamental anterior tiene también ansias propias de élite, espiritual y material.

Por otro lado, además de seleccionar con los jesuitas a un grupo de estudio pertinente, me gustaría aprovechar esta ocasión también para tratar un tema del mundo mediterráneo que, de modo particular, ofreciera la oportunidad de reflexionar sobre un problema cultural de alcance trascendente. La Companía de Jesús, pues, ofrece no solamente una producción notable en términos científicos -en nuestro caso etnográficos, como gramáticas y vocabularios indígenas, informes y libros sobre sus costumbres, viajes cartográficos...- sino la oportunidad de que estudiemos algo mejor las condiciones en que surje o se desarrolla propiamente el conocimiento etnográfico. Como orden, o grupo constituido de personas educadas en un sistema determinado -el humanismo clasicista-, sirve de magnifico ejemplo para "falsar" —o verificar - la teoría de Rowe sobre los orígenes

2 VICENTE MAROTO, Isabel, y Esteban PINERo, Mariano: Aspectos de la ciencia aplicada en la España del siglo de oro. Salamanca: Junta de Castilla y León, 1991. LAFUENTE, Antonio, «Las expediciones científicas del setecientos y la nueva relación del científico con el Estado", en págs. 13-18 de Pino DIAZ, F. del (Coord.) Ciencia y contexto histórico nacional en las expediciones ilustradas a América. Madrid: C.S.I.C., 1988. Salió este libro el año anterior como núm. 180 de la Revista de Indias. Lafuente ha dedicado mucha atención a la ciencia desarrollada por marinos españoles, lo mismo que Horacio Capel a los marinos y a los ingenieros, por tratarse de un grupo amplio y permanente, merecedor de una mayor atención. Cf. de CAPEL, H., Geografia y Matemáticas en la España del siglo XVII, Barcelona: Oikos-Tau, 1982. Del af́o siguiente es su excelente estudio La fisica sagrada: creencias religiosas y teorias científicas en los origenes de la geomorfología española. Siglos XVIr-XVII. Barcelona; Serbal, 1983, donde el autor considera importante la contribución de los jesuitas y de otras órdenes religiosas, como grupos intelectuales en contraste. Desde hace tiempo, los congresos espafioles de Historia de la ciencia incluyen una sesión de instituciones, y así también se hace en la obra magistral de LOPEZ PIÑERO, José Maria, Ciencia y Técnica en la sociedad española de los siglos xv y XVI. Barcelona, E. Labor, 1979.

Hispania, LV/, núm. 192 (1996) 29-50 
renacentistas de la Antropología occidental ${ }^{3}$, que he defendido y aplicado en varias ocasiones desde mediados de los 70 . A saber, que fue el clasicismo quien permitió superar el etnocentrismo cultural previo de los europeos etnocentrismo común a toda la humanidad--, y que se aplicó especialmente a América - evento histórico poco posterior- produciendo entonces cuasi "ex nihilo" una magnífica bibliografía etnográfica. En el caso jesuítico, una orden reconocidamente clasicista, se trata además de un grupo internacionalmente reconocido, ya que no sólo produjeron seguramente más obras etnográficas que otro grupo de tipo misional sino que, sobre todo, se vieron más divulgadas por el mundo ("Cartas edificantes y curiosas", Joumal de Trevoux, etc.).

Frente al énfasis empirista acostumbrado en el enfoque teorico que se ha impuesto en la historia tradicional de la antropología - y en la Etnohistoria americanista particularmente: de ahí la consecuente confianza preferencial en informes tempranos, anónimos y desprejuiciados-, siempre me ha interesado una historia de la etnografía «de autor" —que la considere como «ciencia", como teoría y sistema, y que también atienda a sus prejuicios y opiniones previas-. más que una historiografía científica anónima, como suma de conocimientos para acumular hoy distintas monografías, especialmente de interés regional. La producción jesuíta permite a este respecto, además de buenos materiales, estudiar con cierta trasparencia (casi en forma epanopticas) un proceso exitoso - y muy anómalo- ocurrido en la Europa Moderna donde no sólo se logran nuevos datos etnográficos, sino sobre todo una nueva visión del mundo.

Estas notas introductorias se ofrecen aquí a modo de contexto global solamente, y como expresión de un punto de partida, porque se trata del punto de vista desde el que trabajo. Procederé simplemente a mostrar algunos elementos que he podido desarrollar un poco más, y que son expresivos--debo reconocerlo - tanto de mi propio interés por los cuadros de conjunto como de mis limitaciones personales y disciplinares (este contraste, entre el deseo y la realidad cercana, posiblemente pueda ayudar a entender mejor por qué pongo tanto énfasis en este tipo de enfoque panorámico).

Antes de cerrar esta introducción, debo declarar que en mi entorno percibo hacia los jesuítas un cierto prejuicio negativo - generalizado entre intelectuales hispanos --, o al menos una actitud de desconfianza. Como orden religiosa, tuvo ya desde su creación la competencia de otras (especialmente de parte de los franciscanos como misioneros, y de los dominicos como intelectuales), y hay todavía evidencias innegables de una larga rivalidad sostenida en ambos campos (misional e intelectual) con éstas y con otras órdenes o grupos religiosos -en este momento, por ejemplo, con el Opus Dei. Aquí quisiéramos mostrar solamente una opción sociológica —es decir, reconocer un

3 ROWE, J. H., «The Renaissance Foundations of Anthropology» American Anthropologist, 1: (1965) 1-19. Descubri este artículo modélico en 1974, a punto de concluir mi tesis doctoral, pero sirvió para vertebrarla. La apliqué tempranamente en PINO, Fermin del, «Canarias y América en la historia de la Etnología primigenia: usando una hipótesis». Revista de Indias, vol. 145-146: (1976) págs. 99-156.

Hispania, LV/, núm. 192 (1996) 29-50 
hecho social-, y no militante, cuando elegimos a este grupo por sus méritos como grupo cultural. A pesar de las prevenciones o preferencias personales por un grupo intelectual u otro -en sí mismo lícitas- de cada uno en la actualidad, sin embargo es general la anuencia que suscitan nombres como el del P. Luis de Molina, del P. Mariana o del P. Suárez en los tratados europeos de ciencia política, su contribución universalmente reconocida a los estudios clásicos, a la historia natural o incluso a la literatura exoticista (Gracián, Kircher, Gilij, etc.)

De otro lado, la competencia o rivalidad que la Compañía de Jesús ha suscitado ha sido también de índole política porque ocupó un gran espacio de poder y de privilegio, que llegó a provocar su expulsion inmediata y general a fines del siglo xvuI de parte de las mismas monarquías católicas que la patrocinaban (con evidente exceso de rigor, posiblemente expresando un miedo instintivo a su antiguo poder institucional). Creo que la expulsión de los jesuítas (consensuada con poco tiempo de diferencia entre las coronas de Francia, Portugal y España, y consentida por el Papado, que disolvió a la Compañía posteriormente por espacio de medio siglo, hasta 1814) ha colocado a todo católico moderno en la tesitura de tener que "desconfiar» de los jesuítas; y pocos se animan hoy a meterlos en la historia de la ciencia, o de la historia cultural, sin algún género de prevencion. Es posible que, incluso hoy en España, todavía los tengamos muy cerca como miembros activos (en la Universidad, y en el propio CSIC), pero esto no nos debería sorprender a la hora de estudiar el pasado científico hispano: su elección universitaria o científica individualmente reiterada —dejando o conservando su lazo eclesial-indicaría precisamente lo que venimos considerando de sus condiciones originales y constantes: que son un grupo de marcada significación intelectual.

Por otro lado, a pesar de que la circunstancia de que haya sido una orden religiosa muy internacional (dependiente especialmente de Roma por el voto de obediencia, y con muchos componentes extranjeros en nuestras misiones o colegios, hispanos y americanos) puede invitar también a que pensemos que no forma parte especial de nuestra historia nacional, es un hecho indudable que una gran parte de sus componentes originarios fueron hispanos (Ignacio, Laínez, Borja, Polanco, Nadal, Fco. Javier, etc.), y también una serie de personajes claves suyos en el pasado (Acosta, Gracián, Hervás, Arteaga, Andrés, etc.); lo mismo puede decirse en otro período especialmente brillante de la etapa más cercana (el P. Arrupe, por ejemplo, a partir de 1965), Algunos opinan hoy que la presencia hispana es precisamente la que ha inclinado la balanza en los tiempos recientes para recuperar su espíritu original ${ }^{4}$.

4 Mencionaré solamente dos manuales franceses que sostienen esa tesis, para evitar partidismos nacionales. Guichard, Alain, Les Jésuites. Paris: B. Grasset, 1974, y LeCRIVAIN, Phillippe, Pour une plus grande gloire de Dieu. Les missiones jésuites. Paris: Découvertes Gallimard, 1991. Todos ellos consideran la etapa posterior a 1814 como un viraje, infiel a sus origenes, hacia la desconfianza cristiana en sí mismo y en los fieles, imitando a sus enernigos los jansenistas. La obra del P. Arrupe a partir de 1965 significó un retorno a la libertad de conciencia y al atrevimiento moral que habían caraterizado a la orden inicialmente, en ambos casos por la acción española. 
Ellos, no obstante, han sido en cierto modo influyentes sobre la cultura mundial, a través de su labor educadora de élites (Descartes, Calderón de la Barca, Quevedo, Fontenelle, Raynal, Voltaire, Antonio de Ulloa, etc. fueron alumnos suyos), y eso les hace cosmopolitas. Los franceses en particular tienen por suyos a los jesuítas, como he podido comprobar personalmente: tanto porque sus padres fundadores se educaron en La Sorbonne (y decidieron nacer como grupo en Montmartre) como porque han sido muy importantes posteriormente en sus colegios nacionales, y en sus misiones de Canadá,

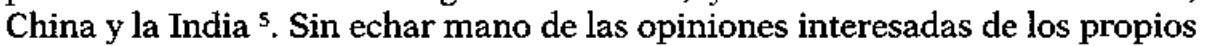
jesuítas, y acudiendo a un manual de historia de la Antropología ilustrada francesa como el de Michèle Duchet, se constata mejor la enorme importancia intelectual adquirida en la Francia ilustrada con un simple detalle: "Casi todos los filósofos fueron alumnos de jesuitas" $"$.

Puede ser sorprendente para nuestra academia hispana que se haya defendido en Oxford, en una investigación doctoral seria, la estrecha connivencia en París de jesuitas y filósofos durante la primera mitad de siglo, hasta la salida de la Enciclopedia -unidos ambos grupos entre sí por una fé en la naturaleza y racionalidad humana, más que con los propios jansenistas, al contrario que en España- ${ }^{7}$; pero no era de extrañar esta convivencia intelectual en la opinión actual de Francia, donde se propuso seriamente desde hace tiempo la incidencia jesuita en la historia nacional, incluso sobre las mismas ideas enciclopedistas y revolucionarias ${ }^{8}$. De modo que, si no al principio - en que la Compañía tuvo dificultades de desarrollo en Francia, y que la propia corte romana y francesa los consideraba una quinta columna de la corona española-, en los siglos XVI y XVII sí puede decirse que los jesuitas han sido considerados como intelectuales propios. Siguiendo una máxima de su

5 Detecté la posición patrimonialista en el misionólogo H. BERNARD-MAITRE, y algo menos en el caso del historiador de los estudios humanisticos, F. DAINVILLE. No obstante, es cierto que la intelectualidad francesa siempre ha tenido a los jesuitas en un pedestal intelectual, que no ha sido tan frecuente en España. ¿Será que nadie es profeta en su tierra? ¿O será que realmente la estructura tradicionalmente aristocrática de la academia y de la sociedad francesa -que tanto denuncia el provinciano Pierre Bourdieu- ha propiciado esta superior aceptación?

6 Antropología e Historia en el siglo de las Luces. Madrid: Siglo Xxu, 1975, pág. 69.

7 NoRTHEAST, Catherine, «The Parisian Jesuits and the Enlightenment, 1700-1762). Studies on Voltaire and the Enlightenment, 288. London, 1991, passim, especialmente el cap. de conclusiones. Una gran parte del pensamiento regalista en Espafia era de tendencia jansenista, y desde luego muy enfrentado a la Compañia; particularmente llamativo el caso del sabio Gregorio Mayans, acérrimo enemigo del humanismo jesuítico, a quien atribuye la decadencia de las Humanidades y de la ciencia en España - posiblemente por su supuesto afrancesamiento. Cf. las numerosas obras de Antonio Mestre, François LOPEZ, etc. Al respecto, también MENENDEZ y Pelayo tiene luminosas aclaraciones en el t. II, págs. 476 de La Ciencia española, Madrid: Ediciones de obras completas, 1933. Recogido en las págs. 148-149 de Miguel Gascon, S. J.: Los jesuitas en Menéndez Pelayo, Valladolid: Libreria Santarén, 1940.

8 DUMRRI, A. «Influence des Jésuites considérés comme misionaires sur les Mouvement des Idées au xvII" siècle». Mémoires de l'Academie de Dijon, Partie des Lettres, $3^{\mathrm{e}}$ série, t. II, 1874, págs. 1-33.

Hispania, LV/, uúm. 192 (1996) 29-50 
fundador, ellos se adaptan a las exigencias de cada país: en Francia dan intelectuales (no sólo en la época ilustrada sino en la actualidad: por ejemplo el filósofo postmoderno Michel de Certeau) y en España proveen al país de télogos ortodoxos o de la liberación, mártires y profesores universitarios para los paises de Centroamérica, párrocos comunistas de suburbios madrileños, o incluso esposos inteligentes y cultos para las viudas de la alta aristocracia.

\section{HUMANISMO Y CONOCIMIENTO CIENTÍfICO}

Cuando usamos el término «humanismo» nos referimos ahora en especial a la actitud favorable a los estudios de Humanidades, como estudios introductorios basados en el conocimiento sistemático de los clásicos: por eso le añadimos "clasicista", para evitar malentendidos. No nos referimos, pues, a una actitud filantrópica cristiana, ni siquiera al estudio genérico de ciertas disciplinas «literarias», sino más bien a un modo literario - humanístico- de concebir el mundo y el saber, basado precisamente en la lectura y comentario crítico de textos clásicos. A pesar de la conocida ambigüedad y polisemia del término, lo seguimos manteniendo por estar convencidos de la pertinencia de este significado primigenio. Como ya hiciera hace años el profesor López Piñero:

"El término «humanismo" (tan equívoco o más que el de «Renacimiento») vamos a utilizarlo, a falta de otro mejor, para designar el movimiento que intentó recuperar el saber de la antigüedad clásica, conectando directamente con sus textos científicos mediante ediciones depuradas filológicamente y traducciones directas, libres de las incorrecciones que tenían las medievales... Con la misma intención en principio - para ver ejemplificadas las doctrinas clásicas- se procedió también a relacionar su contenido con la observación de la realidad (...) la comprobación de lagunas y contradicciones condujo a la crisis del criterio de autoridad como base del conocimiento científico» 9 .

Este tipo de programa de estudios, implantado en la Compañía de Jesús directamente procedente de los modelos humanistas italianos, significaba una revolución intelectual típicamente occidental que no siempre hemos valorado sus herederos del siglo $\mathrm{XX}$, ni incluso hemos percibido a veces cómo era realmente. No se trataba solamente de leer a nuevos autores antiguos o a nuevas versiones textuales de los mismos, o de prestarle más atención que en el pasado, sino de hacerlo de un modo sistemático y con una nueva función. En el caso que nos ocupa de los estudios históricos, y aplicándolo por ejemplo a la enseñanza, ésta se realizaba indirectamente: era ofrecida en forma de comentario de texto y no como conocimiento directo y formal, ya conservado en un manual o en alguna bibliografía determinada. No estaba conformado en manuales el saber histórico, pues, sino que había que construirlo ad hoc, a

9 Ciencia y Técnica en la sociedad española de los siglos xи y xhI, Barcelona, Ed. Labor, 1979, 150-151.

Hispania, LVI/, núm. 192 (1996) 29-50 
partir de unos textos clásicos cuya comprensión reclamaba ese conocimiento previo o contextual. Véase cómo lo explica el P. Dainville:

\begin{abstract}
"Mais pour retrouver et comprendre ce qu'etait pour lors l'histoire dans «l'institution" [=educación] de la jeunesse, il faut quitter nos conceptions d'aujourd'hui. On chercherait en vain, en effet, la mention d'un cours ex professo, dans les programmes ou les horaires, ou quelque manuel. L'Histoire s'apprenait par la lecture des historiens classiques (...) Partout où l'humanisme s'est introduit, les maîtres expliquent "les historiens" classiques, dont les éditeurs multiplient les éditions (...) C'est le mérite de l'humanisme italien d'avoir, dés le debut du $\mathrm{xv}^{\mathrm{e}}$. siècle, dépassé la beauté formelle des oeuvres littéraires pour chercher dans les textes d'histoire de l'Antiquité et, mieux, pour élaborer à leur tour thistoire des Etats, dont l'origine remontait après la fin de l'histoire ancienne" (subrayado nuestro): 10 .
\end{abstract}

A veces, la interpretación actual que se hace del Humanismo o del Clasicismo confunde este punto de vista -que es el que le caracteriza verdaderamente- con el contenido. Lo que caracteriza este movimiento intelectual de comienzos de la Edad Moderna no es que se engrosen los estudios literarios clásicos, en sí mismos, sino el hecho de que se les adopta como base de una concepción global del mundo: una vez establecido un "modelo" cultural paradigmático, los humanistas podían asomarse al mundo desde él, y podían construir entonces un "mundo nuevo". Ese mundo se refería no solamente al campo de los estudios históricos, sino a la estética, a la política, a la moral, a las devociones, a la tecnología, etc ${ }^{11}$.

En el campo del conocimiento científico, por ejemplo, esta manera de proceder condujo a muchos humanistas a aprovechar el proceso de edición o traducción de las fuentes clásicas (Dioscórides, Ptolomeo, Estrabón, Galeno, Plinio, Aristóteles, etc.) para incorporar al libro original sus propias observaciones y experiencias personales. Así, por ejemplo, es como algunos sabios españoles muy conocidos dieron rienda suelta a sus experimentos, o tomaron pie en este estudio glosador para escribir sus textos propios, fundacionales de la propia disciplina anatómica, médica, botánica, geográfica, filosófica, o política: Laguna y Monardes con Dioscórides, Hernández con Plinio, Servet con Ptolomeo, Nebrija con Estrabón y Columela, Vallés con Galeno, o Sepúlveda con Aristoteles. Este fenómeno típicamente humanístico, que ha sido concebido por algunos como prueba evidente de la sujeción esclava al principio de autoridad, comienza a ser considerado en toda su originalidad por especialistas como López Pinero, que lo ha analizado con cierto detalle en 1979 - disciplina a disciplina- como la liberación de la autoridad de los

10 DANVILLE, «L'enseignement de l'Histoire et de la Géographie et la 'Ratio Studiorumn'», Analecta Gregoriana, vol. LXX, (1954) 126 y 129 (1954).

11 Para una descripción más sistemática del Humanismo y sus tratadistas contemporáneos, $c f r$. el preliminar elaborado por Jesús BUSTAMANTE en su estudio del humanismo franciscano de Fr. Bernardino de Sahagún, págs. 245-255 de BERTA ARES y otros: Humanismo y visión del otro en la España moderna. Madrid: C.S.I.C., Biblioteca de Historia de América, 12, 1992.

Hispania, LVM, núm. 192 (1996) 29-50 
clásicos, promovida directamente por «la estela de Nebrija». Una parte de los sabios hispanos en varias ciencias físicas y naturales del siglo xv habían sido efectivamente sus discípulos, directos o indirectos.

Llama la atención el seguimiento minucioso del profesor Piñero sobre el efecto benéfico de los textos clásicos en el avance científico moderno y experimental dentro de cada una de las ciencias analizadas en su manual (matemáticas, cosmografía, náutica, física o filosofía natural, ingeniería, mineralogía, historia natural, anatomía, botánica, etc.), planteando de forma particularmente detallada el caso de la anatomía y medicina, su campo historiográfico propio:

«Este proceso, que se produjo en la mayor parte de las disciplinas, se manifestó de manera especialmente clara en algunas materias como la anatomía humana (...) el acercamiento humanístico a los textos morfologicos de Galeno fue la raiz directa de la reforma vesaliana que impuso un saber anatómico atenido a lo observado en la disección de cadáveres humanos y abiertamente enfrentada con la autoridad de las doctrinas galénicas (151)

Bajo el influjo de las traducciones del griego al latín de las obras anatómicas de Galeno, París se había convertido en el centro de la anatomía galénica pura (...) pero al margen de ella alcanzó gran importancia la práctica de las disecciones privadas [Laguna, Vesalio, Tagault...] (...) La estructura general de su libro y la mayor parte de su contenido [Anatomica methodus, de A. Laguna, 1535] son extrictamente galénicos, lo que no impide que incluya los resultados de sus observaciones de cadáveres humanos (...) (págs. 312-313)

El apoyo en la nueva anatomía para examinar cuestiones fisiológicas por parte de los médicos de mentalidad humanista aparece de forma especialmente clara en la obra de Francisco Vallés [Controversiarum medicarum et philosophicarum libri decem, 1556] (...) Como buen seguidor del galenismo humanista, Vallés se esfuerza en basarse en los textos clásicos, conocidos directamente «in codice graecon, y no oculta su prejuicio ante los árabes y sobre todo ante la tradición medieval de los "barbari». Pero, junto a ello, concede un excepcional relieve a los datos anatómicos. El recurso a ellos considera además, que no ha de hacerse de modo librescon (pág. 335-336) (subrayados míos)».

Pero, evidentemente, el fenómeno no es privativo de la anatomía, y se manifiesta del mismo modo en los otros campos científicos, como por ejemplo en la historia natural:

«Las ediciones de textos científicos griegos no fueron abundantes en la España de la época. En el área que nos ocupa [historia natural], una de las más notables fue la de la Theriaca de Nicandro de Colofón preparada por Pedro Jaime Esteve (1522) (...) Alterna el griego con la traducción latina y amplios comentarios en los que se anotan las localidades y nombres valencianos de numerosas plantas (...) Dentro de esta corriente, la obra sobre historia natural de mayor relieve fue, sin duda, la traducción castellana con comentarios de la Materia Medica de Dioscorides, realizada por Andrés Laguna (...) no solamente se preocupó de establecer un texto griego lo más depurado posible, sino que comprobó en la realidad las descripciones de Dios. corides, herborizando en numerosos lugares de Europa y en distintas zonas del Mediterráneo (...) Por otra parte, ni por la novedad de sus materiales, ni por el detalle de sus descripciones, esta obra puede equipararse a los estudios sobre el Nuevo Mundo de los grandes naturalista antes citados. (1979: 299) (subray. míos)». 
El principal naturalista hispano citado anteriormente es Francisco Hernández, conocido médico de Felipe II enviado en la década de los 70 a México en busca de plantas medicinales, que trajo abundantes pinturas, esqueletos, esquejes y descripciones, al mismo tiempo que traducía completa la Historia naturalis de Plinio el Viejo ${ }^{12}$. Hemos querido subrayar por nuestra cuenta todas aquellas frases que se refieren al efecto imprevisto -e incluso contradictorio, en la interpretación tradicional del humanismo- producido por la lectura crítica de los textos clásicos en relación con la «experiencia personal». A veces se presenta así la experiencia a lo largo del libro de L. Piñero, como efecto imprevisto ( "junto a ello", "lo que no impide", "al margen de ella», etc. o fórmulas más chocantes); pero -como se expresaba él mismo, al principio de nuestra cita referida al caso vesaliano- tal efecto debería ser "directo" ( «la raiz directa», pág. 151). Como lo dió también a entender previamente en un apartado introductorio, la superación posible contra los clásicos solamente podía provenir del conocimiento profundo de los mismos, siendo en los demás casos una simple suma empírica de fenómenos nuevos (sobre materias desconocidas por los clásicos, como la brújula o el continente americano) ${ }^{13}$.

Hacía falta previamente señalar en el caso de las ciencias naturales este fenómeno intelectual -es decir, el aprovechamiento y consciencia de la limitada experiencia mediterránea de los clásicos por parte de sus herederos renacentistas, como ruptura que posibilitará la superación científica-, para que se pudiera ahora explicar mejor la revolución que se opera en el campo de las ciencias humanas, cuando el conocimiento de la humanidad mediterránea dentro de su relativa variedad - se pretende aplicar al resto del mundo recíen conocido: un mundo nuevo, descubierto gracias a los debates y nuevas técnicas humanísticas (cosmografía, náutica, etc.) surgidas en contraste y estudio con los precedentes antiguos.

12 El profesor PTÑERo cita esta traducción de Hernández al final de su biografía, (pág. 288) y de pasada advierte de su importancia "parecida a la versión que ... hizo Andrés Laguna de ... Dioscom rides», pero sin conectar con su viaje americano. Tampoco es realmente destacada ésta de Hernández entre las traducciones españolas de Plinio (págs. 298-300) - -porque quedó manuscrita-ni se analiza su correlación dialéctica con el trabajo experiencial en México, donde justamente se realiza; a pesar de que es allí precisamente donde se añaden comentarios biográficos y críticos imprescindibles para el estudio de Hernández. Creemos que el paradigma y prestigio «experiencial» - como hecho autónomo y precursor de una corriente expedicionaria - del viaje americano de Hernández anuló la correlación propuesta anteriormente por Piñero entre textos y experiencia.

13 En el capítulo introductorio aludido, «Experiencia y razón frente la autoridad de los clásicos» (págs. 163-168) — para mí, clave del magnífico texto histórico y enciclopédico ofrecido por el profesor PTNERO- el paradigma empirista de la experiencia —como reacción espontánea, autónoma respecto de los textos autorizados - se ofrece en realidad como si no estuviera conectada genéticamente con el clasicismo, a pesar de previas afirmaciones contundentes. Ninguna experiencia, que se haga independientemente de una tradición dada — sin conocerla —, puede pretender impugnarla, y es por eso que debe esperar a su utilización por los conocedores de la misma, para ejercer esa crítica. ¿Qué hubiera sido de la experiencia americana de Fernández de Oviedo sin el precedente de Pedro Mártir, y sin sus correspondientes epistolares italianos Ramusio o Bembo? El personaje Oviedo ha sido oportunamente rescatado de su supuesto empirismo espontáneo, enriquecido en su faceta italianista por Antonello Gerbi: La naturaleza de las Indias nuevas. México, Fondo de Cultura Económica, 1978.

Hispania, LVI/, nùm. 192 (1996) 29-50 


\section{HUMANISMO Y MISIONOLOGÍA JESUTTA. UN PROBLEMA DE HISTORIA CULTURAL COMPARADA}

El fenómeno humanístico afectó de forma notable al sector de los misioneros, que escribieron sus gramáticas indígenas aplicando el modelo de la gramática latina, o castellana, de Nebrija: este fenómeno es bien conocido, pero ha sido interpretado con frecuencia como una típica "desviación" europocéntrica, especialmente por la escuela crítica de historia de la lengua. Desviación europocéntrica, por proceder de un proyecto imperialista que pretendía usar la lengua como instrumento de poder; y europocéntrica también, por construir las gramáticas ajenas sobre el patrón de la propia -es decir, sobre el latín, lengua madre europea-. Suele con frecuencia emplearse en apoyo de esta "función imperial» el famoso inicio del prólogo a su Gramática de la Lengua Castellana, donde usara Nebrija aquellas palabras aparente. mente premonitorias del descubrimiento americano:

"Cuando bien conmigo pienso, muy esclarecida Reina, y pongo delante los ojos el antiguiedad de todas las cosas que para nuestra recordación y memoria quedaron escritas, una cosa hallo y saco por conclusión muy cierta: que siempre la lengua fue compañera del imperio; y del tal manera lo siguió, que juntamente comenzaron, crecieron y florecieron, y después junta fue la caída de entrambos» ${ }^{14}$.

No es el momento de detenernos a hacer un minucioso ensayo interpretativo -que seguramente lo merece, por el uso frecuente y equívoco que se hace de esta frase-, pero debemos decir ahora, al menos, que la relación establecida por el autor entre lengua e imperio en este caso es propiamente de tipo histórico evolutivo (que todos los imperios como el judío, griego y latino, antes que el castellano, han contemplado una mejora de su lengua, al mismo tiempo que su propio éxito político), y que nada se dice de tipo funcional, como se deduce bien del texto citado y del subsiguiente razonamiento. Cuando se aborda al final del mismo prólogo una argumentación específicamente funcional (que tal gramática servirá para escribir dignamente las gestas castellanas, para aprender mejor latín, y para que la aprendan los pueblos vencidos por Castilla y los que tienen «trato y conversación" con españoles), esta última función la atribuye Nebrija a las sugerencias anteriores del obispo de Avila, no a sí mismo. Desafortunadamente, con apresurada antelación, una gran parte de los glosadores de este texto lo atribuyen a su proyecto de controlar las gramáticas del Nuevo Mundo, por estar dicho en 1492. Pero la gran noticia no llega a España en este mismo año del 92, y solamente puede referirse la alusión del título de la dedicatoria a la "Reina y señora natural de España y las islas de nuestro mar» a las islas Canarias, recién conquistadas para lo corona de Castilla. Lo de «nuestro mar» seguramente tienda a emular el otro «mare nostrum» de los romanos, el mediterráneo.

14 Uso ahora la versión de Antonio QuLls, Madrid, Ed. Nacional, 1981. 
Contra esta intepretación desafortunada, pero extendida, ha reaccionado recientemente Wolfgang Reinhard, historiador alemán del colonialismo, en un trabajo excelente sobre «Dominio de la lengua y dominio del mundo. Lengua y lingüística en la expansión europea" ${ }^{15}$. Después de una comparación detenida entre los sistemas de control imperial de las lenguas mundiales más comunes, y en particular de la hispana, se pasa revista al trabajo de los misioneros y se compara con otros procedimientos misionales, occidentales y no occidentales (islámicos, hindúes, chinos, etc.), concluyendo que el sistema occidental - y el hispano particularmente- ha sido diferente, precisamente por la participación del Humanismo en el proceso de traducción interlingüistica. Los misioneros no europeos, por definición, no traducen su mensaje evangélico a otras lenguas. Esta diferencia ha permitido a España no solamente conservar las diversas lenguas indígenas del imperio a través de las gramáticas, y proporcionarles incluso una infrecuente beligerancia a la hora de la independencia política (caso del guaraní en Paraguay, debido al estudio jesuítico), sino incluso avanzar hasta una comprensión intercultural. Me interesa destacar ahora -quiero recordarlo otra vez- no tanto el carácter filantrópico de este gesto por parte de los misioneros, como la virtualidad intercultural proveída por el Humanismo:

«Mientras los misioneros de la Edad Media poseían un buen conocimiento del latín, de las lenguas extranjeras tenían conocimientos mediocres, adquiridos sobre el lugar por medio de intérpretes, y sólo con fines prácticos: evidentemente de un estudio de las lenguas no se puede hablar en ningún caso, pese a los ocasionales buenos propósitos. Los misioneros jesuitas ${ }^{16}$, por el contrario, hicieron acopio durante su formación de todas las conquistas de la filología humanista, y estaban (...) en condiciones de transmitir las categorías y técnicas de la filología humanista a otras lenguas. Sus gramáticas y diccionarios de las lenguas del Nuevo mundo salen al mismo tiempo, e incluso antes, que los de las lenguas europeas (...)

Aunque indirectamente, la depurada filología humanista de Occidente ha proverdo el medio decisivo para hacer efectivo el dominio de la lengua, no tanto en el sentido de una elemental glotofagia [como afirman los estructuralistas franceses, en la línea de Foucault] sino como una forma sutil en que los europeos, a través del aprendizaje de las lenguas, penetran en el mundo espiritual de los indios con fines propios (...)"

No sólo se trata pues, de la posibilidad nueva de construir una gramática indígena, cosa que en sí podríamos también subrayar por la novedad del

is REINHARD, Wolfgang, «Sprachbeherrschung und weltherrschaft. Sprache und Sprachwissenschaft in der europaïschen Expansiony, en RENHARD, W.: Humanismus und Neue Welt. Acta Humaniora, VCH, Bonn, 1987, págs. 1-36. Debo agradecer la colaboración de la investigadora del Instituto Sarmiento (Salannanca) Lilia Frieiro, por su excelente traducción de este trabajo, a incluir en un monográfico que tengo en preparación sobre «Humanismo y Antropología».

16 Empleamos una cita oportuna de Reinhard (passim) en que se refiere particularmente a los jestrítas - a los que destaca realmente-, pero no quiero hacer decir al autor que sean solamente los jesuítas los cultivadores del aprendizaje linsglístico. El se refiere en general a los misioneros europeos, particularmente a los católicos.

Hispania, LVII, nưm. 192 (1996) 29-50 
sistema: para el siglo xvi ya se habían elaborado en América 5 gramáticas y 7 diccionarios, y en el xVI respectivamente 14 y 6 . Para darse cuenta de la novedad lingüística que esto representa en Europa, debe notarse que para 1586, cuando se hace la primera gramática inglesa por William Bullokar, se habían publicado en castellano ya cuatro sobre lenguas americanas (tarasco, inca, nahuatl y zapoteco). Antes de la primera de ellas, el zapoteco (1558), solamente se habían gramaticalizado -aparte del griego, el latín, y el castellano de Nebrija - 7 lenguas: en orden cronológico, el árabe (Alcalá de Henares, 1505), el hebreo, el italiano, el francés, el arameo, el checo, el portugués y el caldeo o etíope. La primera gramática francesa había sido escrita en inglés (1521), la segunda en latín (1531), y solamente la tercera lo fue en francés (1550). La mayor parte de las gramáticas de los siglos xvi-xvi para describir lenguas ajenas se escribieron en latín (25), incluyendo las de polaco (1568), alemán (1573), esloveno (1584) o galés (1592). Pero inmediatamente le sigue el castellano como lengua gramaticalizadora (21), y de lejos el portugués (5) y el inglés (2). En esta misma época se usó casi exclusivamente el castellano para describir lenguas americanas y filipinas, con la sola excepción de dos brasileñas (en portugués: una ellas por el canario Anchieta), y una norteamericana (en inglés). A nivel continental, finalmente, en este mismo período sólo hubo 23 gramáticas de lenguas europeas, cantidad seguida de cerca por 21 americanas, 11 asiáticas y 4 africanas ${ }^{17}$.

Como decíamos, no se trata simplemente de una gesta gramatical propiamente dicha, sino de haberla realizado sin traicionar unas condiciones mínimas de comprensión interlingüística. Ello ha sido posible gracias al entrenamiento clasicista de los misioneros católicos, sobre todo en el caso de los jesuítas, que son puestos reiteradamente de ejemplo en este trabajo. Pero, por el momento, más que destacar su conocida participación me interesa analizar las consecuencias derivadas de esta actividad interlinguística para la constitución en Occidente -a partír de una experiencia mediterránea- de una antropología comparada, por elemental que sea:

«El dominio acabado de la lengua, bajo la presión permanente de la traducción directa e inversa, ha debido surtir su efecto sobre la lengua y sobre la manera de

17 Datos tomados de Reinhard que los toma generalmente de Rowe, J. H. «Sixteenth and Seventeenth Century Grammars", en Dell HYMEs (Ed.) Studies in the History of Linguistic. Traditions and Paradigms. Bloomington/London: Indiana Univ. Press, 1974. Aunque ni Reinhard ni Rowe lo precisan, del cómputo de 62 gramáticas censadas en los siglos XVI-XVI --solamente se mencionan las primeras escritas de cada lengua - puedo reconocer 10 que sean jesuítas: del Tupi, Guarani y Kariri de Brasil; Araucano, Milcayac y Allentiac de Chile; Japonés y Canarín de Asia; Bretón, y Lusatiano de Checoeslovaquia. Naturalmente, no se tienen en cuenta el total de gramáticas escritas durante los siglos XVI-XviII sobre América, Asia, Africa u Oceania, la mayor parte de las cuales fueron a cargo de jesuitas. Por eso no resulta inexplicable que quien pueda recopilar la suma mayor de tales diccionarios y gramáticas a fines del siglo XVIII sea el jesuita expulso Lorenzo Hervás y Panduro, en su Catálogo de las lenguas de las Naciones Conocidas (6 tomos, Madrid, 1800-1805: edición ampliada de su publicación italiana, 1784). Cf. para comprender el valor científico de esta obra la edición cuidada por J. Bustamente de la versión italiana, unas notas propias y los estudios póstumos recopilados de Antonio Tovar: El lingüista español Lorenzo Hervás. Madrid: Sociedad General Española de Libreria, S. A., 1986. 
pensar de Occidente (...) Puesto que la traducción supone explicación e interpretación, era de esperar que una cultura para la cual la traducción fue durante siglos una cuestión vital, también haya desarrollado un refinado arte de interpretación. La utilidad de este arte se hace evidente en el trato desprejuiciado con culturas extrañas, así como en la justificación de los propios procedimientos (...) Esto mismo es lo que los europeos han aprendido de la tarea de poner en consonancia el Antiguo con el Nuevo Testamento. Exégesis de textos sagrados hubo en otras partes, pero para el Corán o para los Vedas podía bastar una fidelidad ahistórica a la letra; no así con el cristianismo, porque no puede soslayar la diferencia histórica de los textos (...) ¿Es posible que este tipo de «training” intelectual de los misioneros que protagonizaron la expansión europea no haya surtido ningún efecto? La investigación no ha reconocido hasta ahora el problema de una comparación intercultural de hermenéuticas, ni siquiera en cuanto tal problema, motivo por el cual se debe desistir de esta investigación, después de estas pocas indicaciones.

(...) No es que los europeos hayan pensado de una manera menos etnocétrica que otros, pero a diferencia de los demás, hubo en el etnocentrismo europeo tradicional un alto grado de agilidad intelectual que les permitió entrar en lenguas y culturas extranjeras, hasta alcanzar el entusiasmo de un jesuíta canadiense, que llegó a decir de la lengua algonquina: «He descubierto todos los secretos de una de las lenguas más bellas del universon. ¿Habría sido posible que un representante de otra cultura [no occidental y humanista] hiciera esta afimación?"(Reinhard, passim, cursivas nuestras)».

Es cierto que este género de interrogantes y de comparaciones interculturales, a que nos lleva el estudio del humanismo mediterráneo clasicista pudiera ser acusado de "etnocentrismo antropológico" por un oriental occidentalizado tan conocido como Edward W. Said: ${ }^{18}$ pensar que sólo en Occidente, y a partir del Humanismo clasicista, se ha podido dar una "visión del otro" positiva. Pero lo cierto es que, incluso considerado desde un punto de vista meramente lingüístico, Occidente ha tenido una capacidad excepcional de curiosidad intercultural. Said debiera reconocer en todo el amplio movimiento orientalista de Occidente - a pesar de su invención homogeneizadora de los otros, a los que aglutina como uorientales" - un hecho positivo, y es su rara y temprana curiosidad por el mundo oriental (y también por el mundo árabe e islámico: que es de quien se ocupa especialmente Said, amparado en el paraguas orientalista). Ese hecho debe ser reconocido de modo que ayude a configurar nuestra imagen completa del orientalismo - y no nos haga caer en una visión simplificadora, idéntica a la impugnada - Bernard Lewis -un estudioso del mundo árabe bien reconocido, aunque del todo contrario en sus valoraciones a Said-dedicó un libro justamiente al proceso de conocimiento oriental respecto del mundo occidental, y su impresión final es clara:

18 Orientalism, N. York: Pantheon Books, 1978. Traducido en 1990 por Ediciones Libertarias, Madrid, con presentación de Juan Goytisolo. El autor, estudiante y profesor de literatura comparada en Estados Unidos, ha sostenido múltiples polémicas con antropólogos como Ernest Gellner, en el suplemento literario del Times. Cf. la lúcida reseña de James Clifford en History and Theory, 1980, págs. 202-223. De Gellner, famoso antropólogo inglés y estudioso del mundo árabe, se ha traducido en Ediciones Paidos (Barcelona, 1994) un texto expresivo de este debate, aunque no menciona a Said: Posmodernismo, razón y religión, Barcelona, Ediciones, Paidos, 1994.

Hispania, LVl/1, aúm. 192 (1996) 29-50 
"A la fin du xvm" siècle, au moment où se situe la première incursion d'un Etat européen moderne dans l'Orient arabe, l'étudiant occidental dispose d'une somme importante de documents sur le Moyen-Orient (...). De l'autre cöté, en revanche, on ne trouve rien de comparable. LArabe, le Persan ou le Turc ne dispose d'aucun dictionaire ni d'aucune grammaire d'une langue européenne, sous forme manuscrite ou imprimée... Le premier diccionaire d'arabe et d'une langue européenne, dû à un indigène arabophone, est publié en 1828. C'est l'oeuvre d'un chrétien (copte égyptien), «revue et augmenté» par un orientaliste français et destiné, comme le dit l'auteur dans le préface, à un public occidental platot qu'arabe (Paris, 1828-29). L'idée que ce genre d'ouvrages pût être utile aux Arabes ne semble s'ëtre imposée que bien des années après" ${ }^{19}$.

Si bien puede parecer un poco sumaria la comparacion de la apertura respectiva de Oriente y Occidente, y algo idealista en su juicio de la tolerancia occidental, no cabe duda del acierto por lo que hace al analisis meramente lingüístico, como reconoce incluso Maxime Robinson en el posfacio o eṕlogo puesto a la traducción francesa. Reconocimiento valioso, porque procede de un crítico que posee una versión muy opuesta al propio Lewis.

En un tono parecido al de Said, como decfamos, muchos analistas de gramáticas misionales han querido desautorizarlas como trabajo intercultural, acusándoles de basarse en un molde ajeno, el latino. Sin centrarse en los jesuitas especialmente, aunque reconociendo también su contribución lingùística, el profesor J. H. Rowe ha analizado particularmente este fenómeno latinizante de las gramáticas misionales, para terminar quitándole la importancia que le han querido conceder los censores contemporáneos:

"Las lenguas no europeas eran estudiadas principalmente por misioneros cuya meta era "reducirlas» - como se decía en la terminología contemporánea- al patrón de la gramática latina... Este procedimiento era el más natural, dado que la única preparación de la mayor parte de los primeros escritores de gramáticas para su trabajo era el latín —que entonces era la base de la educación, tanto de los paises protestantes como católicos-.

(...) La tendencia latinizante era muy fuerte, pero no deberia exagerarse. Lebrija, en su gramática española de 1492, hizo un intento de describir, al menos, algunos de los rasgos de la lengua espafiola en sus propios términos ... Un gramático actual, que intente usar estas obras tempranas, descubre que puede casi generalmente reinterpretar correctamente el material presentado en este marco latino, si bien puede bloquearse ante el tratamiento tan deficiente dado a la fonología, y por el hecho de que algunas formas y construcciones ajenas al latín no se recogenn 20 .

19 Comment l'Islam a découvert l'Europe. Paris, La Découverte, 1984, págs. 181-182. Manejo la versión francesa, que es la que conozco, pero me interesa especialmente por contener el juicio de Maxime Rodinson, y por proceder de Francia mucha parte de la crítica al orientalismo occidental. Temiendo traicionar el texto original, en un tema intercultural y vidrioso como el presente, lo dejo en francés. Se ha traducido recientemente una obra cordinada por este autor: El mundo del Islam. Gente, cultura, fe. Ediciones Destino, 1995.

20 Rowe, «Sixteenth and Sevententh Century Grammars», op. cit., pág. 365. Traducción nuestra.

Hispania, LVII, nu்m. 192 (1996) 29-50 


\section{JESUITAS, CLASICISMO Y ANTROPOLOGÁ. EL SURGLIENTO DE UNA TRADICIÓN COSMOPOLITA, A PARTIR DEL MEDTTERRÁNEO}

Nosotros quisiéramos retraer nuestro interés del campo de la lingúrstica al propiamente etnográfico, una vez considerado el efecto revolucionario previo del Renacimiento sobre el conocimiento científico en general, y sobre el conocimento lingǘstico en particular. Vamos a referirnos brevemente a algún elemento favorable a la Etnografía en que los jesuitas han sido particularmente responsables, aunque no tengamos espacio para dar muchos detalles ni argumentos. Nos referiremos solamente a aquellos elementos propios de la Etnografía o Antropología relacionados con el Humanismo.

La Antropología se caracteriza por algunas cualidades en su modo de estudio, que le hacen reconocible por las demás disciplinas. Ante todo, requiere un conocimiento personal del terreno en que viven las comunidades estudiadas, y supone la visita prolongada al territorio hasta adquirir la familiaridad de lo conocido a fondo, adoptando la óptica local. En segundo lugar, se supone que esta información se ordenará en un modelo o cuadro global, que tendrá en cuenta la totalidad del contexto cultural en que ocurre la vida de esa comunidad. Este modelo debe permitir un cuadro comparado de las sociedades conocidas, que nos ayude a clasificar las sociedades de acuerdo a sus semejanzas y diferencias, y a sus grados de proximidad en los diferentes apartados de su cultura. Esta valoración de cada sociedad por comparación se ayudará del conocimiento ya adquirido sobre las sociedades tradicionales y de la antigüedad, de manera que su conocimiento devenga estratégico en el proceso de conocimiento de las nuevas sociedades. Lo que se pretende con ello es una doble meta: por un lado, derruir los conceptos etnocéntricos que nos impiden comprender las nuevas sociedades, y por otro, adquirir una mayor familiaridad con la evolución que han sufrido las sociedades humanas en el tiempo en el conjunto de casos reunidos, viejos y nuevos.

Todas estas pinceladas que ofrezco sobre la naturaleza de la Antropología tienden a permitir una valoración disciplinarmente connotada -aunque pueda parecer "presentista" - del género de conocimiento jesuítico de las Indias orientales y occidentales. Evidentemente, no podemos decir extricto sensu que el conocimiento de los misioneros jesuítas del siglo xvi sea per se antropológico o etnográfico; pero esta rigurosidad terminológica no debe servir para llamarle "geográfico» o «histórico" al tipo de noticias que ellos ofrecen, simplemente porque usan este término humanístico de "geografía" o "historia"; no deberíamos conformarnos con esa denominación disciplinar actual, ya que los contenidos reales de esta información geográfica o histórica en el Renacimiento no coincidían con los actuales.

Si uno se detiene a examinar el tipo de noticias que demandaba el P. General a sus subordinados jesuitas de la India oriental a menos de 10 años de la fundación de su orden, se advierte un tipo de intereses que trasciende normalmente la geografía, y entra claramente en la lingüística o la etnografía. Ignacio de Loyola pedía a Francisco Javier a fines del año 1547 que le enviase noticias

Hispania, LV/, núm. 192 (1996) 29-50 
detalladas desde Goa acerca «del aire, el alimento, las costumbres de los hombres y la naturaleza de las lenguas" 25 . Como es bien conocido, estos interrogatorios fueron respondidos, y se hizo obligatorio en la Compañía informar al P. General cada cuatrimestre primero, y cada año después, de los éxitos y fracasos misionales. Tales informes han sido reunidos parcialmente en una amplia colección de "Monumenta histórica S.I.», modelo de edición documental en pleno siglo $\mathrm{xx}$; pero más importante es que una gran parte fue publicada ya desde mediados del siglo xvi, constituyendo la conocida colección de ucartas edificantes y curiosas", pasto del que se nutrieron abundantemente los escritores europeos con afanes antropologicos (Montesquieu en particular, hasta el punto de ser criticado en ello por Voltaire, que también dependía ampliamente de esas fuentes). ¡Ojalá las demás órdenes religiosas, y las demás instituciones civiles con intereses en el Nuevo Mundo (Consejo de Indias, por ejemplo) le hubieran imitado, aunque fuera con sus mismas intenciones apologéticas! ${ }^{22}$

No cabe duda del paralelismo que este género de noticias guardaba con los intereses del Consejo de Indias hispano, donde se establece (1539) el cargo de cosmografo mayor - poco antes de la carta de Ignacio a Francisco Javier-y se comienza a pedir a los diferentes enclaves indianos exactamente el mismo tipo de informes enciclopédicos que los jesuŕtas, con énfasis en los aspectos etnográficos. Merecería la pena establecer algún día una correlación entre unos y otros interrogatorios, entre sí contemporáneos y muy semejantes, y posiblemente se compruebe que su tremendo parecido se debe, aparte posibles contactos personales inverificables, a una misma formación humanista de los jesuítas que asesoran a S. Ignacio en Roma respecto a la de los asesores hispanos del Consejo de Indias (Pedro Mártir, Hernando Colón, Juan Páez de Castro, Alonso de Santa Cruz, López de Velasco, etc.). El tipo de brevedad de estas alusiones de S. Ignacio se parece, por ejemplo, a la Real Cédula enviada a la Audiencia de México, a fines de 1533 para reunir noticias geográficas y etnográficas:

«Porque queremos tener entera noticia de las cosas de esa tierra (...) de las calidades y extrañeza que en ella hay (...) poniendo sus ritos y costumbres particularmentes ${ }^{23}$.

21 Monumenta Ignatiana, vol I, págs. 648-649. Tomo la cita del DANVILE, P. François: Les Jesuites et leducation de la société française. La Géographie des Humanistes. Paris: Beauchesne et ses fils, 1940, pág. 113. Solamente cinco años después, se piden los mismos datos al P. Nóbrega en Brasil: «de la región, del clima, de los grados, de las costumbres de sus habitantes, de sus vestidos, habitaciones... todo ello, menos por satisfacer una curiosididad, por lo demás legítima, como porque el $\mathrm{P}$. General pueda tomar sus decisiones con perfecto conocimiento de causa, en caso necesarion. Jbidem. Retraduzco.

22 La afirmación de que las otras órdenes religiosas no le imitaron la toma $F$. Dainville de Ludwig Pastor, t. XVIII de su Historia de los Papas (versión francesa, pág. 232), y sobre el secretismo del Consejo de Indias, basta consultar la Historiografia Indiana de F. EsTEVE BARBA (Madrid, Gredos, 1966 y reed. 1992), para saber el control oficial de los textos de cronistas (Zárate, Gómara, J. B. Muñoz, etc.), y la cantidad de manuscritos sin publicar que dejaron sus cronistas, privados y oficiales. Sobre el uso reiterado de las «cartas anuas» jesuitas por los filósofos franceses, se hace eco sistemático M. Duchet, op. cit. , passim.

${ }^{23}$ Solano, F. de, (Ed.) Cuestionarios para la formación de las Relaciones Geográficas de Indias, siglos XVI/KIX. Madrid: C.S.I.C., 1988, pág. 4. 
Y puestos a comparar, quizá los cuestionarios misioneros parezcan más antropológicos que los del cosmógrafo real, si creemos al P. Dainville:

«(..) las encuestas geográficas de los misioneros presentan dos caracteres muy importantes para entender los desarrollos de la Geografía entre los jesuitas (...). Las directivas emanadas de Ignacio y sus sucesores les orientan francamente hacia una 'geografía del hombre' (...) esencialmente sobre los hombres con quienes van a vivir y tratar, y sobre los géneros de vida a los que deberán adaptarse ellos mismos (...)

(...) el segundo carácter de sus relatos es que se refieren menos a lo que es raro que a lo que es típico (...) no lo anormal y excepcional sino al contrario, lo habitual, la moda común, el tipo (...) sobre los trazos generales que caracterizan un medio y definen la vida de cada lugar de la tierra (...) (Ello) confiere a sus observaciones un valor científico verdadero, y pertenenecen ya a la geografía moderna (DAINVILLE, 1940: 120-121, traducción mía)"

Evidentemente, el título de la obra que escribe el P. Dainville le obliga a colocar estas encuestas entre los trabajos de "geografía», pero nada le impediría reconocer su mérito etnográfico. El hecho de que se concentren sus intereses informativos en el hombre, y particularmente en su cultura cotidiana y ordinaria (tratada no como monstruosidad, como cosa atípica, sino como modo de vida) le acerca sobremanera al género de escrito antropológico. Son conocimientos tomados en el lugar, conociendo su lengua e integrando los elementos culturales en un conjunto que les da sentido. $\mathrm{Y}$ las nuevas sociedades son comparadas sistemáticamente, entre sí y con las sociedades europeas. Una característica jesuíta es la comparación permanente de sus descripciones indianas con las sociedades antiguas, especialmente con las del período clásico, en un intento de comprender ambas mejor. Esta fue la meta reconocida por el P. Lafitau para escribir su famoso libro comparativo entre Iroqueses y Griegos o Romanos, que le ha valido un puesto fijo en las historias profesionales de la Antropología. Oigamos a Michèle Duchet, autoridad en la materia, lo que dice de su contribución innovadora:

"La obra del padre Lafitau sobre las Moeurs des sauvages américains comparés aux moeurs des premiers temps (1724) ordena una masa de informaciones considerable, conforme a un método que ya no es analítico, sino sintético: al comprobar palabra con palabra, las creencias y los usos separados entre si, en el tiempo, por siglos o, en el espacio, por obstáculos infranqueables, pone las bases de una ciencia del hombre universal; substituye una perpectiva histórica y geográfica por una perspectiva antropologica (...) es significativo que haya sido a través de la etnologia comparada como la humanidad exotica, presente desde hacía dos siglos en los horizontes del pensamiento moderno, entro en el campo del saber. Sus costumbres y creencias pierden sólo su extrañeza cuando se las compara con las de los eprimeros tiemposn, de los que nos dejaron testimonios antiguos (...) La metamorfosis del hombre salvaje en primitivo, porque lo convierte en ser histórico, hace posible, por lo mismo, una intención antropológica” (1975: 15-16, cursivas nuestras)

Hispania, LVII, nưm. 192 (1996) 29-50 
Duchet conoce menos la literatura anterior al xvm, y es por eso que puede permitirse considerar las relaciones de los misioneros anteriores al P. Lafitau, aunque mejores que las de otros informantes, como que todavía son aescritas sin orden ni método, y llevan entremezcladas las descripciones de costumbres y usos con el relato de las peripecias del viaje o de la estancian (1975: 15). Ese no es desde luego el caso de una larga serie de escritos misionales sistemáticos como los del dominico Las Casas, del franciscano Sahagín o del jesuíta Acosta, todos los cuales escriben tratados sistemáticos sobre la religión y la civilización de pueblos americanos, usando el cotejo reiterado con las del mundo grecoromano, más conocidas para ellos. Por sólo poner un caso, elijamos el del jesuita Acosta -en tantas cosas precursor de su cofrade Lafitau - que usa el ejemplo grecoromano para el mismo efecto, es decir para «metaformosear lo salvaje en primitivon, para hacerlo familiar al hombre europeo: ya me he ocupado en otra ocasión de su erudición clásica, y de la sistemática comparación a que somete las culturas americanas con las de griegos y romanos ${ }^{24}$. Hablando de la religiones americanas, advierte en el "prólogo a los libros siguientes» (es decir, el prólogo a los 3 libros restantes de historia moral, tras acabar cuatro de historia natural y geografía en las Indias orientales y occidentales):

«Si alguno se maravillare de algunos ritos y costumbres de los indios (...) o los detestare por inhumanos y diabólicos, mire que en los griegos y romanos - que mandaron el mundo- se hallan o los mismos u otros semejantes, y a veces peores, como podrá entender fácilmente no sólo de nuestros autores [cristianos] Eusebio Cesariense, Clemente Alejandrino, Teodoreto Cirense y otros, sino también de los mismos suyos, como son Plinio, Dionisio Halicarnaso y Plutarco*.

Lo mismo recuerda de modo introductorio en el libro VI de su «Historia natural y moral» sobre sus instituciones políticas indianas -de su "policía", dice Acosta, remedando el término griego politéia - en que vuelve a echar mano de la comparación entre pueblos nuevos de América y pueblos viejos del Mediterráneo:

"(..) en su ley tenían muchas cosas de bárbaros y sin fundamento, pero había también otras muchas de consideración... Y no es de maravillar que se mezclasen yerros graves, pues en los más estirados de los legisladores y filósofos se hallan, aunque entren Licurgo y Platón entre ellos». (libro VI: capítulo 1)

Por último, para terminar este muestra de iniciativas etnográficas del Nuevo Mundo relacionadas con la cosmovisión previa del mundo mediterráneo, quisiera referirme a un modelo descriptivo que comparten los escritos jesuítas con el tipo de esquema que se va imponiendo en las «crónicas de Indias», y en los escritos cosmográficos «de oficio» pedidos por el Consejo de Indias: me interesa mostrar ahora solamente que tal modelo no está

24 "Culturas clásicas y americanas en la obra del Padre Acosta», (t. I, 327-362), en F. DE Solano y F. dEL Pino: América y la España del siglo xV. Madrid: C.S.I.C., 1982.

Hispania, LV/I, aim. 192 (1996) 29-50 
desconectado de las intenciones antropológicas de los autores. Me refiero al modelo de "historia natural y moral de las Indias», que fue acuñado en el título por la obra del P. Acosta (1590), y que a partir de entonces se hará común hasta comienzos del siglo $\mathrm{xIX}$, alternando el uso del binomio «natu$\mathrm{ral} / \mathrm{moral}$ " por otros parecidos (natural/civil, física/política, etc.).

El interés simultáneo por la cosmografía y la historia $\longrightarrow$ o por las cosas de naturaleza y las del hombre- es casi un tópico de los escritos indianos, desde Colón mismo. Creo que no se ha considerado hasta donde vale el carácter revolucionario que le atribuyó el historiografo Edward Fueter:

«Los descubrimientos y las conquistas en América plantearon a la historiografía un problema enteramente nuevo (...) Lo que les interesaba [a los lectores] no eran tanto los detalles de la conquista como los pueblos y los paises maravillosos descubiertos por los europeos (...) Deseaban descripciones y cuadros (...) Ejercieron una gran influencia sobre la historiografia general. Unicamente después del descubrimiento de América y de los primeros relatos acerca del Nuevo Mundo, se adoptó la costumbre de iniciar las historias de los pueblos europeos con una descripción detallada del país y de sus habitantes (...) Es así como el interés etnográfico despertado por el descubrimiento de América ejerce su acción sobre la historia de Europa 25.

Pero en la estructura de los distintos cuestionarios indianos puede decirse que la distinción minuciosa entre historia natural y moral no comienza a ser objeto central hasta el reinado de Felipe II. Con ciertos precedentes - por estudiar- en los intelectuales de tiempos del emperador (Santa Cruz, Zárate, Gómara y Páez de Castro), no será hasta el reinado siguiente cuando se imponga la sistematización de la historia natural y moral. Esto lo veremos reflejado en los cuestionarios del Consejo de Indias, en particular en la normativa general de cuestionarios emanada bajo el gobierno del efímero e inteligente presidente del Consejo, Juan de Ovando (1566-1575): nos referimos a las «Ordenanzas para la formación del Libro de las descripciones de Indias", decretada por el Rey desde S. Lorenzo de El Escorial el 3.VII.1573. Se trata de un documento muy extenso (págs.16-74 de la edicion antes citada) ${ }^{26}$, que contiene instrucciones generales (13 capítulos), un interrogatorio (27 capítulos), y unas largas recomendaciones formales (95 capítulos). Me voy a referir solamente a un apartado relativamente breve del mismo (caps. 17-18, y 81-83), es decir a la distinción entre historia natural y moral.

${ }^{25}$ Historia de la Historiografia moderna. Buenos Ares, 1952 (orid. 1911)

26 SOLANO, F. de, (Ed.) Cuestionarios... op. cit. Nos ha sido especialmente útil el trabajo de Pilar Ponce - alma original de esta colección- sobre las Ordenanzas de 1573, págs. LXXIX-XCII, y también su trabajo inédito en el "Seminario sobre Historia natural y moral», citado en nota 1, dedicado a la persona de López de Velasco - alma de estas ordenanzas, en opinión de la autora-. Se trata, en mi opinión, del documento más extenso y probablemente más importante de toda la colección de cuestionarios indianos, que ya ha merecido otros serios estudios anteriores, de parte de J. Manzano e I. Sánchez Bella, valorando la acción de Ovando.

Hispania, LVII, núm 192 (1996) 29-50 
La primera de ellas debe interesarse en "las naciones de hombres que hay, y las naturalezas y calidades de ellos, animales de la tierra.... pescados de las aguas...,insectos y serpientes..., árboles..., hierbas silvestres..., mineros..., [y] enfermedades que hay en cada tierra.... . Por lo que hace a la historia moral -equivalente claro de la etnografía en la terminología de la época- se refiere tanto a la conquista española - significado posterior de la «historia civil o política»- como, sobre todo - más importante para el autor, a juzgar por la mayor extensión que le dedica--, a la historia indígena o etnografía: «especialmente los descubrimientos y conquistas... y por quién..., las naciones de los naturales que las habitaron y habitan, los reinos y señoríos que hubo en cada caso, y los límites... y las diferencias de lenguas que tenían, la forma de república..., la religión y adoración que tenían, y las personas... y la forma...». Sigue un larga enumeración de los otros temas a incluir en la historia moral, que va desde el ciclo vital, la comida y bebida, vestidos, casas, propiedades, sucesiones y contratos, delitos y penas, reyes y jurisdicción, un largo epígrafe de tributos y servicios, oficios mecánicos, guerras (igualmente largo), escritura, calendarios, etc.

Nos interesa haber detallado tanto el esquema de este cuestionario de 1573 del Consejo de Indias para señalar a continuación lo interesante que resulta que la obra del P. Acosta -asíduo colaborador del rey desde su regreso de las Indias en 1587- haya sido precisamente la que más de cerca lo haya puesto en práctica, hasta el punto de darle nombre a su obra. Naturalmente, no es el momento de ofrecer un análisis del binomio natural/moral en Acosta y en la historiografía jesuíta de le época, aunque hay que caracterizarla mínimamenente: porque se trata de una producción típicamente jesuíta -que titularon así normalmente sus obras indianas (desde el P. Cobo a mediados del xvi hasta el P. Gilij o el P. Molina a fines del xvin) - y que se hallaba directamente conectada con las categorías aristotélicas (obras de la naturaleza y obras del hombre) traducidas por la escolástica humanista de los jesuitas ${ }^{27}$.

Lo que nos ofrece este modelo descriptivo enciclopédico, dentro del cual cabe una etnografía ortodoxa (ubicada entre la historia de los animales superiores del Nuevo Mundo y la de la llegada occidental, en términos de temas de jerarquía creciente), es todo un cuadro global de la naturaleza, que atribuye a cada tema (ritos, sacrificios, dioses...) un lugar apropiado. A su vez, y dentro de una filosofía jerárquica y evolucionista del ser - al mismo tiempo que funcionalista, por la "ratio" teleológica que le define, estando cada ser inferior al servicio del superior: todo al servicio del hombre- nos permite no solamente descripciones detalladas - acompañadas a veces de gráficos-, sino reflexiones

27 A este respecto, debo a la investigación de mi colaborador Francisco Castilla, participante en el Seminario antedicho, la duda de que el esquema se debiera directamente a Aristóteles -que nunca escribió una obra binomial de animales y hombres- sino más bien a la intepretación escolástica y del Renacimiento. De hecho, asi lo confïrma Arthur O. Lovejoy, en su cap. IL, dedicado a los origenes griegos de la idea analizada: La gran cadena del ser. Historia de una idea. Barcelona: Icaria Editorial, especialmente pág. 77. 
orgánicas que favorecen la comparación sistemática entre los seres de cada lugar y los de otros lugares.

Sin profundizar más por ahora en este interesante asunto, creo que el modelo jesuita de historia natural y moral de las Indias - al mismo tiempo que su afán comparado entre el Viejo y el Nuevo Mundo, y su empresa descriptiva y divulgativa de las novedades indianas- son una prueba clara de su ubicación ortodoxa en el campo de la Antropología, como efecto de la visión integradora del cosmos producida por el Humanismo clasicista surgido en el mundo cultural del Mediterráneo.

Me gustaría ofrecer como colofón de este trabajo un comentario de Alfred Metraux sobre la contribución preciosa de los jesuítas a la etnografía americana. Elijo esta cita para dejar sentado que mi valoración es absolutamente ortodoxa, dado que Metraux fue el alma del Handbook of South American Indians - la enciclopedia etnográfica americanista de la Smithsonian, aún no superada-y un hombre que solía decir lo que pensaba. Escribió estas palabras en una revista jesuíta, después de haberlo hecho en el propio Handbook, y en diferentes medios de expresión internacional:

"Quienquiera que haya manejado las fuentes sobre Sudamérica de los siglos XVI y XVII no puede evitar ser tocado por las cualidades literarias que caracterizan los documentos jesuitas. La mayoría de ellos están escritos en un lenguaje elegante y claro, y raramente sufren de las oscuridades de estilo que estropean tan frecuentemente otras fuentes (...) El desastre sobrevenido a la orden afectó también a la antropología. Solamente a fines del siglo xxx habrá obras que puedan ser comparadas en valor con las descripciones de costumbres nativas e instituciones escritas por los jesútas, durante los doscientos años que duró su conquista espiritual del continente. De no haber sido por la inteligente curiosidad y el espíritu científico de tantos misioneros jesuitas, nuestro conocimiento de los indios sudamericanos habría sido más magro y superficial» ${ }^{28}$.

28 "The contribution of the Jesuits to the exploration and Anthropology of South America». Por MetrauX, Alfred, Mid-America. An Historical Review, July, (1944), págs. 183-191. (Loyola University, Chicago). Traducción nuestra.

Hispania, LVI, núm. 192 (1996) 29-50 